\title{
A New Approach with Three Dimension Figure and ANSI/IEEE C57.104 Standard Rule Diagnoses Transformer's Insulating Oil
}

\author{
Ming-Jong Lin \\ Department of Electronic Engineering, Southern Taiwan University of Science and Technology, Tainan City, \\ Chinese Taipei \\ Email: 1430107@yahoo.com.tw
}

Received 5 September 2014; revised 25 October 2014; accepted 12 November 2014

Copyright (C) 2014 by author and Scientific Research Publishing Inc.

This work is licensed under the Creative Commons Attribution International License (CC BY). http://creativecommons.org/licenses/by/4.0/

cc) (i) Open Access

\begin{abstract}
The dissolved gas analysis (DGA) is an effective method for detecting incipient faults in immersed oil power transformers. In this paper, we investigate the DGA methods and employ the ANSI/IEEE C57.104 standards (guidelines for the interpretation of gases generated in oil-immersed transformers) and IEC Basic Gas Ratio method to design a heuristic power transformer fault diagnosis tool in practice. The proposed tool is implemented by a MATLAB program and it can provide users a transformer diagnosis result. The user keys in the data of $\mathrm{H2}, \mathrm{CH} 4, \mathrm{C2H}, \mathrm{C2H}$, and $\mathrm{C2} \mathrm{H} 6$ gases dissolved from the immersed oil transformer's insulating oil measured by ASTM D3612. The analyzed results will be represented in texts and figures. The real measured data of the transformer oil were taken from Taiwan Power Company substations to verify the validation and accuracy of the developed diagnosis tool.
\end{abstract}

\section{Keywords}

Power Transformer Diagnosis, Dissolved Gas Analysis, Total Combustible Gases, Distribution Substation (D/S)

\section{Introduction}

Immersed-oil power transformers in the power system play an important role as voltage conversion. The transformer's insulating oil can cool the transformer down and strengthen the ability of power supply. A transformer 
fault will cause electricity interruption and may result in a serious problem. Therefore, detection of transformer's fault is very important task. The insulating oil gas analysis (DGA) is a good way to diagnose the transformer fault and has been widely used by many power companies in the world. This is because that the insulating oil analysis can predict incipient faults via the analysis of the gases generated from the insulating oil. If the transformer's fault can be diagnosed accurately, and then the transformer will be well maintained, the electricity interruption caused by transformer's fault can be avoided.

The insulating oil measurement is via chromatography instrument (ASTM D3612). The measured data of nine kinds of gas, namely Ethane $\left(\mathrm{C}_{2} \mathrm{H}_{6}\right)$, Hydrogen $\left(\mathrm{H}_{2}\right)$, Methane $\left(\mathrm{CH}_{4}\right)$, Carbon Dioxide $\left(\mathrm{CO}_{2}\right)$, Ethylene $\left(\mathrm{C}_{2} \mathrm{H}_{4}\right)$, Acetylene $\left(\mathrm{C}_{2} \mathrm{H}_{2}\right)$, Carbon Monoxide (CO), Nitrogen $\left(\mathrm{N}_{2}\right)$, and Oxygen $\left(\mathrm{O}_{2}\right)$ can be obtained [1]. Any measured data of nine kinds of gas being larger the standard criterion of ASNI/IEEE C57.104 indicated that we have to check what happens in the transformer. In this paper, we investigate the DGA methods and employ the ANSI/IEEE C57.104 Standard Rule and IEC Basic Gas Ratio method to develop a heuristic diagnosis tool which is carried out by a MATLAB program. The user only keys in the measured data of $\mathrm{H}_{2}, \mathrm{CH}_{4}, \mathrm{C}_{2} \mathrm{H}_{6}, \mathrm{C}_{2} \mathrm{H}_{4}$, and $\mathrm{C}_{2} \mathrm{H}_{2}$ and the developed diagnosis tool can provide a diagnosis result by texts and figures.

\section{Transformer Fault Diagnosis}

Total Combustible Gases are made up of $\mathrm{H}_{2}, \mathrm{CH}_{2}, \mathrm{C}_{2} \mathrm{H}_{6}, \mathrm{C}_{2} \mathrm{H}_{4}, \mathrm{C}_{2} \mathrm{H}_{2}$ and $\mathrm{CO}$, and its definition as follows, is shown in formula (1) (unit ppm):

$$
\mathrm{TCG}=\frac{\mathrm{H}_{2}+\mathrm{CH}_{2}+\mathrm{C}_{2} \mathrm{H}_{6}+\mathrm{C}_{2} \mathrm{H}_{4}+\mathrm{C}_{2} \mathrm{H}_{2}+\mathrm{CO}}{10^{6}}
$$

The immersed oil transformer's insulating oil along with the transformer operating time and the measured of the cyclical time has made vital relations with its life-span, however its increase value on IEEE C57.104 standard, as shown in formula (2):

$$
R=\frac{\left(S_{T}-S_{O}\right) \times V \times 10^{-6}}{T}
$$

where, $R$ is increase of the TCG value (a milliliter/day), $S_{T}$ is testing value, $S_{O}$ is previous value, $V$ is measured from the transformer's volume as well as $T$ is measured from the duration of days. So the quantity of the TCG, rely on the R's value which is classified "Normal”, “Attention”, “Abnormal”, and "Danger” etc., four kinds of symptom shown in Table 1.

Be based on Dissolved Gas Analysis (DGA), the value of insulating oil has been diagnosed either normality or abnormality in the body of transformer. In recent years, a lot of techniques have been developed to predict diagnosis for the transformer latent failure points by the gas content, such as the Key Gas method, Duval triangle method as well as Dornenberg method, Roger method, Liner SVM diagnosis etc., this paper took the Diagnosis of IEC Basic Gas Ratio method and ANSI/IEEE Standard Rule to design a Transformer Fault Diagnosis Tool by the MATLAB program which described next sections below.

\subsection{The IEC Basic Gas Ratio Method}

The IEC Basic Gas Ratio method uses 3 sets gas ratios $\mathrm{C}_{2} \mathrm{H}_{2} / \mathrm{C}_{2} \mathrm{H}_{4}, \mathrm{CH}_{4} / \mathrm{H}_{2}$, and $\mathrm{C}_{2} \mathrm{H}_{4} / \mathrm{C}_{2} \mathrm{H}_{6}$ as base to engage in diagnosis. Each ratio is distinguished 6 fault's conditions such as Partial discharges, Discharge of low energy, Discharge of high energy, Thermal fault $\mathrm{t}<300^{\circ} \mathrm{C}$, Thermal fault $300^{\circ} \mathrm{C}<\mathrm{t}<700^{\circ} \mathrm{C}$, and Thermal fault $\mathrm{t}>$ $700^{\circ} \mathrm{C}$. The result according to IEC method is shown in Table 2. The relationship between the fault type and the gas ratio is shown in Table 2. Faults often start as incipient, low energy faults which may develop into more serious higher energy or higher temperature faults. When a fault is detected, it is important to determine the trend in the rate of increase of the gas. An increase in gas values of more than $10 \%$ per month above the normal values will indicate that the fault is active. It is also important to determine the trend in the occurrence of different types of faults, and to detect early, any deterioration towards a more serious fault [2].

\subsection{Diagnosis of Specification for ANSI/IEEE C57.104 Standard}

According to the Diagnosis of Specification for ANSI/IEEE C57.104 Standard, the anomalous properties values 
Table 1. Periodic table of examination for TCG [1] (unit: ppm).

\begin{tabular}{|c|c|c|c|c|}
\hline Case & TCG & Increase & Again Measures Duration & Suggestion \\
\hline \multirow{3}{*}{ Case 1} & \multirow{3}{*}{$\leq 720$} & $>30$ & Month & Normal \\
\hline & & $10-30$ & Season & Normal \\
\hline & & $<10$ & Year & Normal \\
\hline \multirow{3}{*}{ Case 2} & \multirow{3}{*}{$721-1920$} & $>30$ & Month & Attention \\
\hline & & $10-30$ & Month & Attention \\
\hline & & $<10$ & Season & Attention \\
\hline \multirow{3}{*}{ Case 3} & \multirow{3}{*}{$1921-4630$} & $>30$ & Week & Abnormal \\
\hline & & $10-30$ & Week & Abnormal \\
\hline & & $<10$ & Month & Abnormal \\
\hline \multirow{3}{*}{ Case 4} & \multirow{3}{*}{$>4630$} & $>30$ & Day & Danger \\
\hline & & $10-30$ & Day & Danger \\
\hline & & $<10$ & Week & Danger \\
\hline
\end{tabular}

Table 2. The diagnosis of IEC basic code [2].

\begin{tabular}{ccccc}
\hline Case & Characteristic Fault & $\mathrm{C}_{2} \mathrm{H}_{2} / \mathrm{C}_{2} \mathrm{H}_{4}$ & $\mathrm{CH}_{4} / \mathrm{H}_{2}$ & $\mathrm{C}_{2} \mathrm{H}_{4} / \mathrm{C}_{2} \mathrm{H}_{6}$ \\
\hline PD & Partial Discharges & $\mathrm{NS} 1$ & $<0.1$ & $<0.2$ \\
D1 & Discharge of Low Energy & $>1$ & $0.1-0.5$ & $>1$ \\
D2 & Discharge of High Energy & $0.6-2.5$ & $0.1-1$ & $>2$ \\
T1 & Thermal Fault $<300^{\circ} \mathrm{C}$ & NS1 & $>1$ but NS1 & $1-4$ \\
T2 & Thermal Fault $300^{\circ} \mathrm{C}<\mathrm{t}<700^{\circ} \mathrm{C}$ & $<0.1$ & $>1$ & $<4$ \\
T3 & Thermal Fault $\mathrm{t}>700^{\circ} \mathrm{C}$ & $<0.22$ & $>1$ & $<$ \\
\hline
\end{tabular}

Note: NS1 stand for No Significance.

from decomposition of the insulating oil were shown in Table 3.

\section{The New Diagnosis Approach for in Practice}

\section{This Paper Follows the Design Flow Chart (Shown in Figure 1)}

The diagnosis tool of insulating oil can be diagnosed by well usage of different method and specification after incorporating some kinds of human experience. The flow chart of the proposed diagnostic method is shown in Figure 1. With well-designed man-machine interface, the developed program can be implemented by computer to avoid man error and achieve more reliable diagnosis result.

For more simple, precise, and effective to diagnose, I read lots of diagnosis's approach of transformer's insulating oil which were such good paper as "Support Vector Machine-Based Fault Diagnosis of Power Transformer" [4] and "Duval Triangle: A Noble Technique for DGA in Power Transformer" [5], and etc. Eventually, from those methods and approaches were appraised carefully, this paper takes ANSI/IEEE C57.104 Standard Rule and IEC Basic Ratio methods to design the program. The goal is it cans double check to complete accurate diagnosis.

The accuracy of interpretable plots by concept of digital rule establishes during implementation after input the concentration of $\mathrm{H}_{2}, \mathrm{CH}_{4}, \mathrm{C}_{2} \mathrm{H}_{6}, \mathrm{C}_{2} \mathrm{H}_{4}$, and $\mathrm{C}_{2} \mathrm{H}_{2}$. This paper designs a set of highly fast way to diagnose of transformer incipient fault by IEC Basic Gas Ratio and the Standard of ANSI/IEEE C57.104 diagnosis method. From the report's from the obtained texts of the ANSI/IEEE C57.104 standard diagnosis and the figure of IEC Basic Gas Ratio to judge what was in body of transformer. 
Table 3. Gas content in oil diagnostic [3] (unit: ppm).

\begin{tabular}{cccccc}
\hline Name & Content Value & Property & Name & Content Value & Property \\
& $>1801$ & Danger & & $>1001$ & Danger \\
& $>701$ & Abnormal & & $>401$ & Abnormal \\
$\mathrm{H}_{2}$ & $>101$ & Attention & $\mathrm{CH}_{4}$ & $>121$ & Attention \\
& $<100$ & Normal & & $<120$ & Normal \\
& $>151$ & Danger & & $>201$ & Danger \\
& $>101$ & Abnormal & & $>101$ & Abnormal \\
$\mathrm{C}_{2} \mathrm{H}_{6}$ & $>66$ & Attention & $\mathrm{C}_{2} \mathrm{H}_{4}$ & $>51$ & Attention \\
& $<65$ & Normal & & $<50$ & Normal \\
& $>35$ & Danger & $\mathrm{C}_{2} \mathrm{H}_{2}$ & $>2$ & Attention \\
$\mathrm{C}_{2} \mathrm{H}_{2}$ & $>10$ & Abnormal & & $<1$ & Abnormal \\
\hline
\end{tabular}

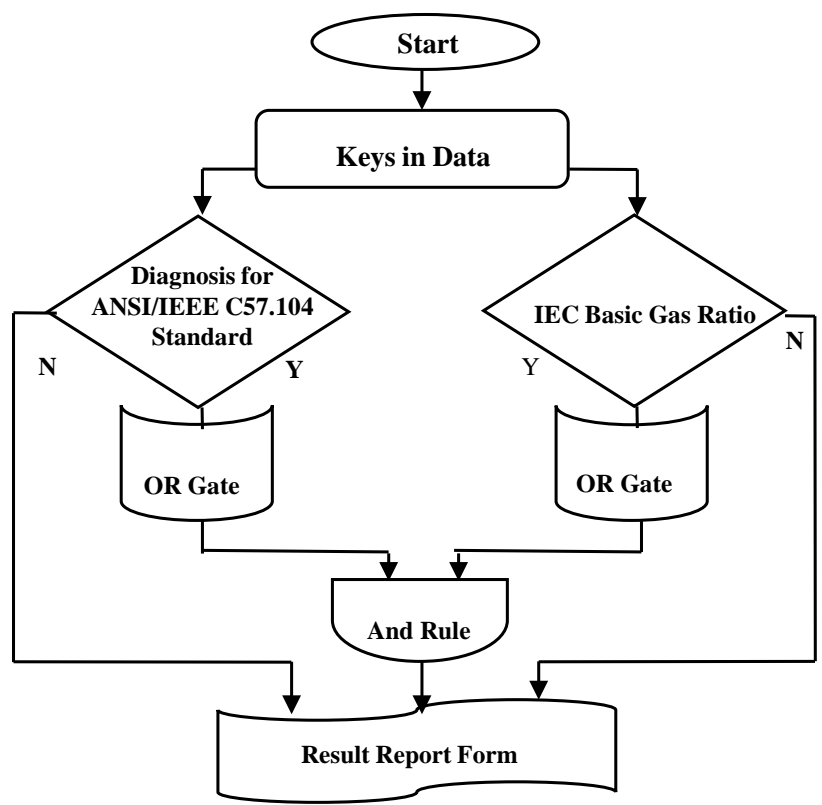

Figure 1. The flow chart of the MATLAB program.

\section{Diagnostic Practices and Verification}

\subsection{Ba Dou D/S \#4DTr Case [6]}

On March 22 ${ }^{\text {nd }}$, 2012 Taiwan Power Company Ba Dou D/S \# 4DTr's insulating oil, inspected these gas component content Hydrogen, Methane, Ethane, Ethylene, and Acetylene data are described (in Table 4), this data (before repair and after repair) were used the program of MATLAB, shown (in Table 5 \& in Table 6) to obtain the result of the judgment by text of ANSI/IEEE standards and plots of the IEC Basic Gas Ratio diagnosis method.

\subsection{Digital Logic}

Keeping in mind when computers work on digital gate that high or low voltage is considered as 1 or 0 . So that using these high or low data is represented for 1 or 0 . Electronic circuits must be designed to manipulate these 
Table 4. Ba Dou D/S \#4DTr gas data (unit: ppm).

\begin{tabular}{cccccc}
\hline Date & $\mathrm{H}_{2}$ & $\mathrm{CH}_{4}$ & $\mathrm{C}_{2} \mathrm{H}_{6}$ & $\mathrm{C}_{2} \mathrm{H}_{4}$ & $\mathrm{C}_{2} \mathrm{H}_{2}$ \\
\hline $\begin{array}{c}\text { 2012.03.22 } \\
\text { Before Repair }\end{array}$ & 100 & 149 & 41 & 401 & 5.3 \\
$\begin{array}{c}\text { 2012.05.21 } \\
\text { After Repair }\end{array}$ & 7 & 6 & 44 & 18 & 0 \\
\hline
\end{tabular}

Table 5. Transformer fault diagnosis tool (Ba Dou D/S \#4DTr before repair).

Diagnosis for ANSI/IEEE C57.104 Standard

$$
\begin{aligned}
&{ }^{* *} \mathrm{H}_{2}==\text { Normal } \\
&{ }^{* *} \mathrm{CH}_{4}==\text { Attention } \\
&{ }^{* *} \mathrm{C}_{2} \mathrm{H}_{2}==\text { Normal } \\
&{ }^{* *} \mathrm{C}_{2} \mathrm{H}_{4}==\text { Danger } \\
&{ }^{* *} \mathrm{C}_{2} \mathrm{H}_{6}==\text { Normal }
\end{aligned}
$$

Diagnosis for IEC Basic Gas Raito

$$
{ }^{* *} \mathrm{C}_{2} \mathrm{H}_{2} / \mathrm{C}_{2} \mathrm{H}_{4}==\text { Normal }
$$

${ }^{* *} \mathrm{CH}_{4} / \mathrm{H}_{2}==$ Discharge of High Energy

${ }^{* * *} \mathrm{C}_{2} \mathrm{H}_{4} / \mathrm{C}_{2} \mathrm{H}_{6}==$ Temperature Fault $>700^{\circ} \mathrm{C}$

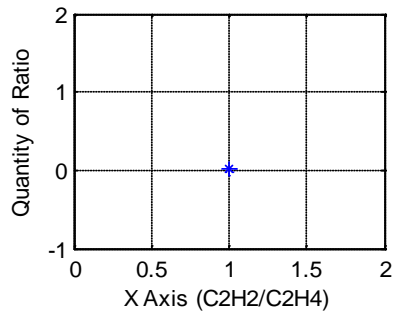

\begin{tabular}{|c|c|c|c|c|}
\hline Name/Ratio & Result of Diagnosis & Digital Symbol & Result of Diagnosis & Digital Symbol \\
\hline $\mathrm{H}_{2}$ & Danger & 1 & Abnormal, Attention, Normal & 0 \\
\hline $\mathrm{CH}_{4}$ & Danger & 1 & Abnormal, Attention, Normal & 0 \\
\hline $\mathrm{C}_{2} \mathrm{H}_{6}$ & Danger & 1 & Abnormal, Attention, Normal & 0 \\
\hline $\mathrm{C}_{2} \mathrm{H}_{4}$ & Danger & 1 & Abnormal, Attention, Normal & 0 \\
\hline $\mathrm{C}_{2} \mathrm{H}_{2}$ & Danger & 1 & Abnormal, Attention, Normal & 0 \\
\hline \multicolumn{4}{|c|}{ Partial Discharges } & 1 \\
\hline \multicolumn{4}{|c|}{ Discharge of Low Energy } & 1 \\
\hline \multirow{4}{*}{$\begin{array}{c}\mathrm{C}_{2} \mathrm{H}_{2} / \mathrm{C}_{2} \mathrm{H}_{4} \\
\mathrm{CH}_{4} / \mathrm{H}_{2} \\
\mathrm{C}_{2} \mathrm{H}_{4} / \mathrm{C}_{2} \mathrm{H}_{6}\end{array}$} & \multicolumn{3}{|c|}{ Discharge of High Energy } & 1 \\
\hline & \multicolumn{3}{|c|}{ Thermal Fault $\mathrm{t}<300^{\circ} \mathrm{C}$} & 1 \\
\hline & \multicolumn{3}{|c|}{ Thermal Fault $300^{\circ} \mathrm{C}<\mathrm{t}<700^{\circ} \mathrm{C}$} & 1 \\
\hline & \multicolumn{3}{|c|}{ Thermal Fault $\mathrm{t}>700^{\circ} \mathrm{C}$} & 1 \\
\hline
\end{tabular}
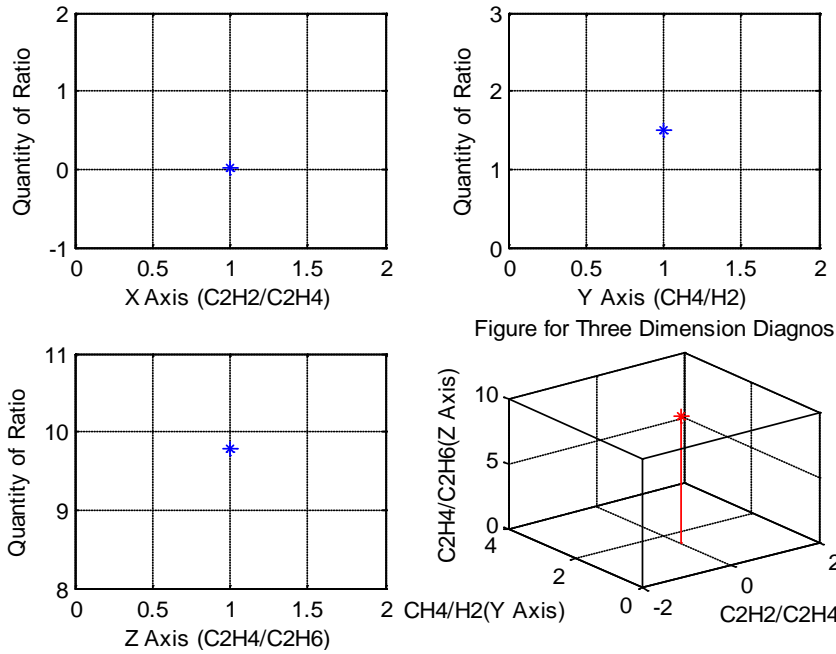

Figure for Three Dimension Diagnosis

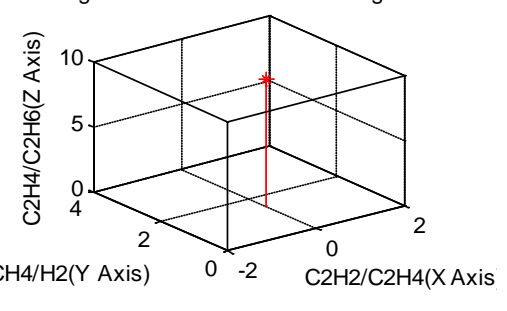

Table 6. Explain for digital symbol with regulating diagnosis. 
positive and negative pulses into meaningful logic (in Table 7). Logic gates are the building blocks of digital circuits. Combinations of logic gates form circuits designed with specific tasks in mind [7]. This paper of blocks of digital circuits is shown (in Figure 2).

To ensure power supply stable quality and safety, the gases of the insulating oil was shown by Truth Table of logic (in Table 8), on $22^{\text {nd }}$ March, 2012 Ba Dou D/S \#4Dtr to fulfill the transformer body maintenance which was found out a losing screw which is shown (in Figure 3) [6]; Especially, on May $21^{\text {st }}, 2012$ Taiwan Power Company Ba Dou D/S \#4DTr's insulating oil, inspected these gas component content Hydrogen, Methane, Ethane, Ethylene, and Acetylene data are described (in Table 4), this data (after repair) was used the program of MATLAB, shown (in Table 9) to obtain the result of the judgment. To justify the program provides a quick diagnosis, the results can be used as a tool of transformer maintenance.

\subsection{Take Some Case to Confirm}

Taking some case (in Table 10, Table 11) from abnormality of transformer's insulating oil those were confirmed through Taiwan Power Company, then these cases were taken to verify the program in practical.

\section{Conclusion}

As we know that, how to detect the transformer fault quickly and accurately is not an easy job. In this paper, we have investigated the DGA methods and developed a quick method to diagnose the malfunction of power transformers by using ANSI/IEEE C57.104 diagnosis specification and IEC Basic Gas Ratio method. We have developed the transformer fault diagnosis tool by a MATLAB program. The real measured data of the transformer oil taken from Ba Dou D/S \# 4DTr transformer of Taiwan Power Company are used to verify the validation and accuracy of the developed diagnosis tool. This tool will be useful for engineers and technicians who are in charge of transformer's maintenance.

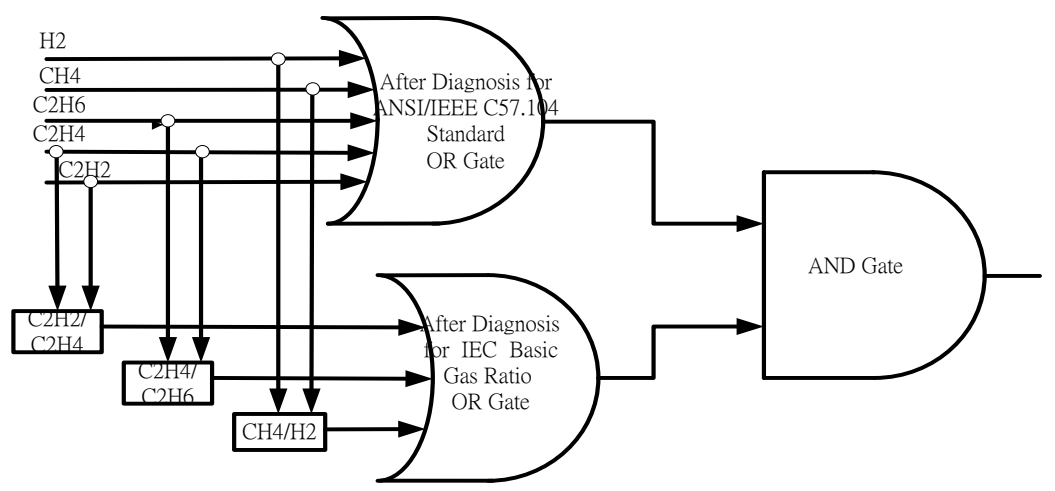

Figure 2. Program for digital flow chart.

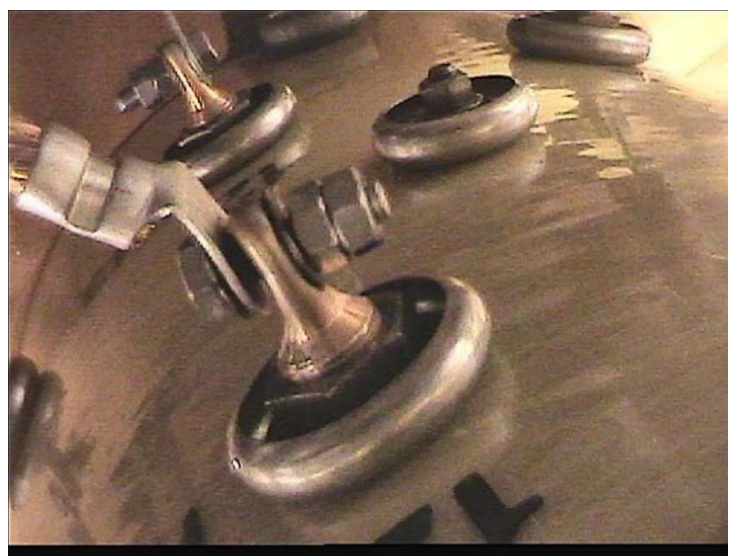

Figure 3. A losing screw. 
Table 7. OR \& AND gate truth table [7].

\begin{tabular}{|c|c|c|}
\hline OR Gate & \multicolumn{2}{|c|}{$\begin{array}{l}\text { Truth } \\
\text { Table }\end{array}$} \\
\hline 11 & & Output \\
\hline & & 0 \\
\hline 0 & & $\frac{1}{1}$ \\
\hline & & 1 \\
\hline Select An Inp & $10 \mathrm{OR}$ & \\
\hline
\end{tabular}

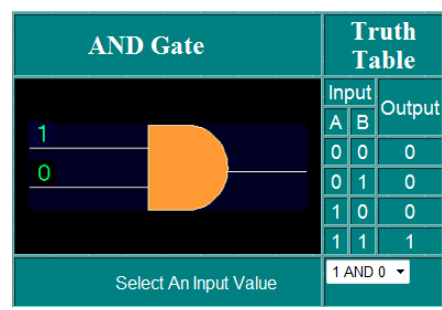

Table 8. Truth table for Ba Dou D/S \# 4DTr's insulating oil.

\begin{tabular}{cccccccccc}
\hline Date & $\mathrm{H}_{2}$ & $\mathrm{CH}_{4}$ & $\mathrm{C}_{2} \mathrm{H}_{6}$ & $\mathrm{C}_{2} \mathrm{H}_{4}$ & $\mathrm{C}_{2} \mathrm{H}_{2}$ & $\mathrm{C}_{2} \mathrm{H}_{2} / \mathrm{C}_{2} \mathrm{H}_{4}$ & $\mathrm{C}_{2} \mathrm{H}_{4} / \mathrm{C}_{2} \mathrm{H}_{6}$ & $\mathrm{CH}_{4} / \mathrm{H}_{2}$ & $\mathrm{OUT}$ \\
\hline 2012.3 .22 & 0 & 0 & 0 & 1 & 0 & 0 & 1 & 1 & 1 \\
2012.5 .21 & 0 & 0 & 0 & 0 & 0 & 0 & 1 & 1 & 0 \\
\hline
\end{tabular}

Table 9. Transformer fault diagnosis tool (Ba Dou D/S \#4DTr after repair).

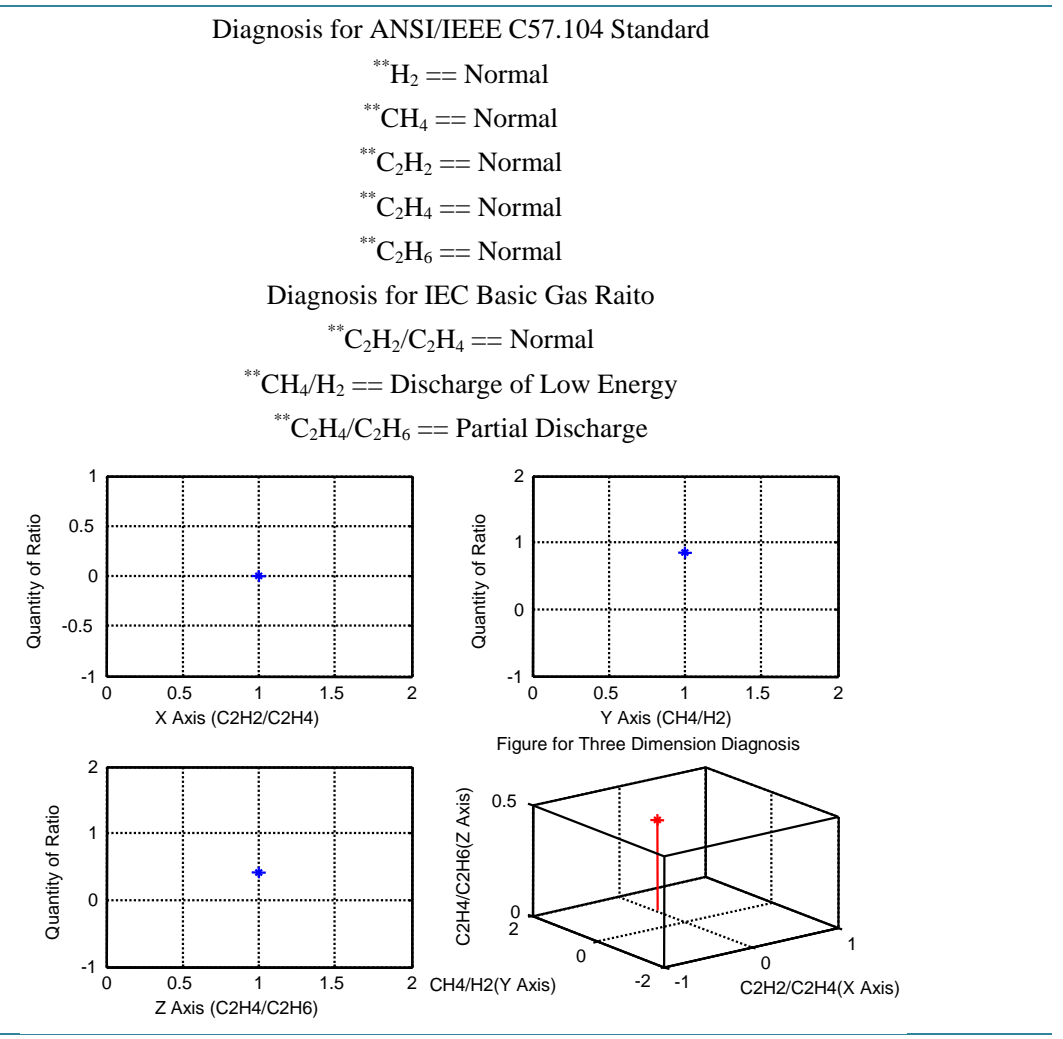

Table 10. Some normality and abnormality of transformer gas data in practical (unit: ppm).

\begin{tabular}{cccccccc}
\hline Date & $\mathrm{H}_{2}$ & $\mathrm{CH}_{4}$ & $\mathrm{C}_{2} \mathrm{H}_{6}$ & $\mathrm{C}_{2} \mathrm{H}_{4}$ & $\mathrm{C}_{2} \mathrm{H}_{2}$ & $\mathrm{CO}$ & TCG \\
\hline $\mathrm{C} 1(2007.05 .10)$ & 44 & 41 & 88 & 7 & 10.1 & 57 & 247 \\
$\mathrm{C} 2(2010.09 .05)$ & 140 & 54 & 79 & 21 & 53.8 & 35 & 388.1 \\
$\mathrm{C} 3(2011.08 .03)$ & 181 & 74 & 84 & 58 & 51.4 & 171 & 619 \\
$\mathrm{C} 4(2011.12 .26)$ & 935 & 271 & 116 & 330 & 420 & 128 & 2200 \\
$\mathrm{C} 5(2012.05 .10)$ & 239 & 346 & 78 & 787 & 24 & 312 & 1786 \\
$\mathrm{C} 6(2012.07 .08)$ & 48 & 694 & 356 & 1077 & 0.4 & 36 & 2211 \\
$\mathrm{C} 7(2013.09 .23)$ & 133 & 211 & 66 & 384 & 1.9 & 411 & 1207 \\
\hline
\end{tabular}


Table 11. Implementation of the results of the program with stand for digital rule in practical.

\begin{tabular}{|c|c|c|c|c|c|c|c|c|c|c|}
\hline \multirow{2}{*}{ Case/Name } & \multicolumn{8}{|c|}{ Diagnosis for ANSI/IEEE C57.104 } & \multirow{2}{*}{$\begin{array}{l}\text { Diagnosis for } \\
\text { Program out }\end{array}$} & \multirow{2}{*}{ Repair State } \\
\hline & $\mathrm{H}_{2}$ & $\mathrm{CH}_{4}$ & $\mathrm{C}_{2} \mathrm{H}_{6}$ & $\mathrm{C}_{2} \mathrm{H}_{4}$ & $\mathrm{C}_{2} \mathrm{H}_{2}$ & $\mathrm{C}_{2} \mathrm{H}_{2} / \mathrm{C}_{2} \mathrm{H}_{4}$ & $\mathrm{C}_{2} \mathrm{H}_{4} / \mathrm{C}_{2} \mathrm{H}_{6}$ & $\mathrm{CH}_{4} / \mathrm{H}_{2}$ & & \\
\hline $\mathrm{C} 1$ & 0 & 0 & 0 & 0 & 0 & 1 & 0 & 1 & 0 & $\mathrm{~N}$ \\
\hline $\mathrm{C} 2$ & 0 & 0 & 0 & 0 & 1 & 1 & 1 & 1 & 1 & Ac \\
\hline C3 & 0 & 0 & 0 & 0 & 1 & 1 & 1 & 0 & 1 & Ac \\
\hline $\mathrm{C} 4$ & 0 & 0 & 0 & 1 & 1 & 1 & 1 & 1 & 1 & Pd \\
\hline C5 & 0 & 0 & 0 & 1 & 0 & 0 & 1 & 1 & 1 & Ac \\
\hline C6 & 0 & 0 & 1 & 1 & 0 & 0 & 1 & 1 & 1 & $\mathrm{Pd}$ \\
\hline C7 & 0 & 0 & 0 & 1 & 0 & 0 & 1 & 1 & 1 & $\mathrm{Pd}$ \\
\hline
\end{tabular}

Symbols: N (Normal), Ac (Arc), Pd (Partial Discharge). 1 (Program out for 1), 0 (Program out for 0), C1 (Case1), C2 (Case2), C3 (Case3), C4 (Case4), C5 (Case5), C6 (Case6), C7 (Case7).

\section{Acknowledgements}

The author would like to thank that the relevant information of this paper was provided by the department of the supply, Tai Pei branch supply, and Research Institute of Taiwan Power Company.

\section{References}

[1] IEEE (2012) C57.104-2008-IEEE Guide for the Interpretation of Gases Generated in Oil-Immersed Transformers. Minutes of WG, Meeting, Nashville, 13 March.

[2] IEC (1999) Guide to the Interpretation of Dissolved and Free Gasses Analysis. IEC Standard 60599, IEC publ. 60599, Mar.

[3] Mollman, A. and Pahlavanpour, B. (1999) New Guidelines for Interpretation of Dissolved Gas Analysis in Oil-Filled Transformers. Electra, CIGRE France, 186, 30-51.

[4] Sahri, Z.B. and Yusof, R.B. (2014) Support Vector Machine-Based Fault Diagnosis of Power Transformer Using k Nearest-Neighbor Imputed DGA Dataset. Journal of Computer and Communications, 2, 22-31. http://dx.doi.org/10.4236/jcc.2014.29004

[5] Singh, S. and Bandyopadhyay, M.N. (2010) Duval Triangle: A Noble Technique for DGA in Power Transformer. International Journal of Electrical and Power Engineering, 4, 193-197. http://www.medwelljournals.com/ref.php?doi=ijepe.2010.193.197

[6] Qi, Y.G., Ming, L.K., Sing, G.B., Sung, S.U. and Xia, S. (2012) Ba Dou D/S \#4DTr Overhaul Report. Taiwan Power Company Institute, Taipei City.

[7] http://isweb.redwoods.edu/instruct/calderwoodd/diglogic/and.htm 
Scientific Research Publishing (SCIRP) is one of the largest Open Access journal publishers. It is currently publishing more than 200 open access, online, peer-reviewed journals covering a wide range of academic disciplines. SCIRP serves the worldwide academic communities and contributes to the progress and application of science with its publication.

Other selected journals from SCIRP are listed as below. Submit your manuscript to us via either submit@scirp.org or Online Submission Portal.
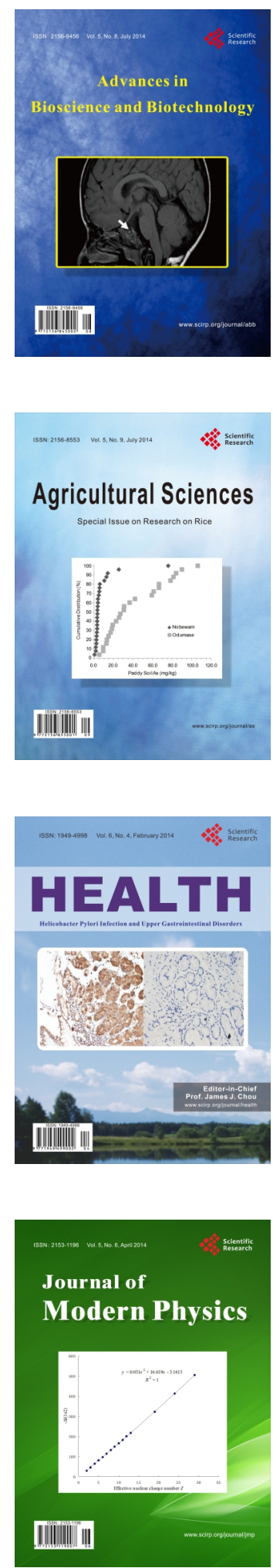
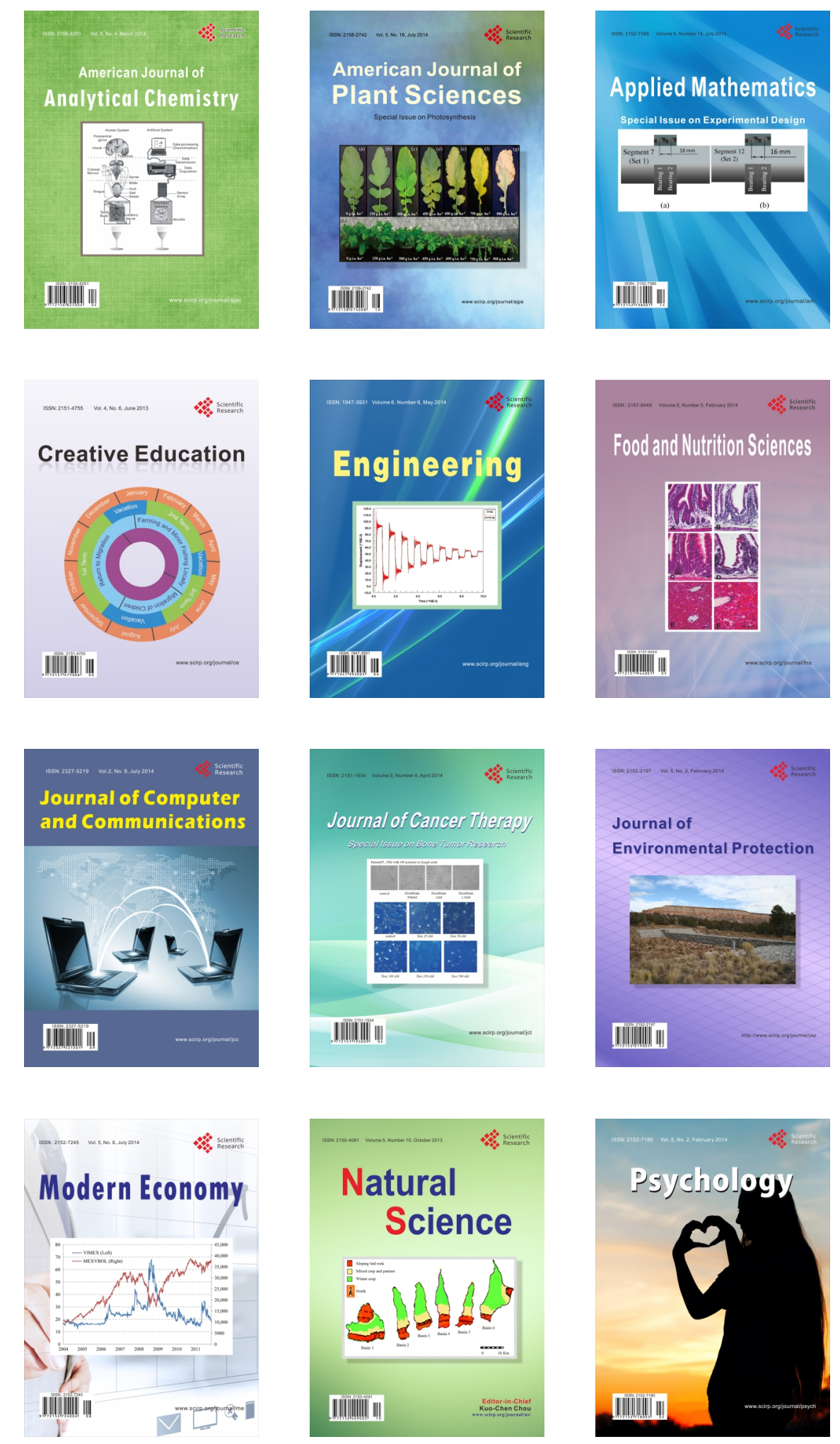